\title{
Chemical Composition and Antifungal Activity of Essential Oil from Xanthium strumarium L. Leaves
}

\author{
Z. PARVEEN* ${ }^{*}$ S. MAZHAR, S. SIDDIQUE, A. MANZOOR ${ }^{1}$ AND Z. ALI \\ PCSIR Laboratories Complex, Ferozpur Road, Lahore-54600, ${ }^{1}$ Institue of Biochemistry and Biotechnology, \\ University of the Punjab, Pakistan
}

\section{Parveen, et al:: Studies on Essential Oil of Xanthium strumarium L. Leaves}

The hydrodistilled essential oil from Xanthium strumarium L. leaves was analysed by gas chromatographymass spectrometry. Nine out of twenty two constituents were identified from $X$. strumarium oil. The main components of the oil were $\beta$-caryophyllene $(17.53 \%)$, $\alpha$-cadinol $(6.66 \%)$, spathulenol $(6.09 \%)$, limonene (5.66\%) and 1,3,5-trimethyl-2[2-nitroallyl]benzene (3.29\%). Phytol (2.42\%), $\alpha$-muurolene (2.08\%), copaene $(1.47 \%)$ were present in appreciable amounts. E,E,Z-1,3,12-nonadecatriene-5,14-diol $(0.27 \%)$ was present in minor amount. The oil displayed high degree of antifungal effect against all fungal strains with 11.8-46.0 $\mathrm{mm}$ zone of inhibition at concentration range $8-250 \mu \mathrm{g} / \mathrm{ml}$. The $8 \mu \mathrm{g} / \mathrm{ml}$ minimum fungicidal concentration along with being the minimum inhibitory concentration points to the potential of $X$. strumarium essential oil as a promising source of antifungal agents with useful biomedical applications.

Key words: Xanthium strumarium L., antifungal activity, essential oil, gas chromatography/mass spectrometry, leaves

Fungal infections account for a high proportion of health problems in developing countries. There are alarming reports of opportunistic fungal infections particularly those of the skin and mucosal surface ${ }^{[1,2]}$. There is
This is an open access article distributed under the terms of the Creative Commons Attribution-NonCommercial-ShareAlike 3.0 License, which allows others to remix, tweak, and build upon the work non-commercially, as long as the author is credited and the new creations are licensed under the identical terms 
an increasing awareness amongst microbiologists and dermatologists pertaining to know the cause of infectious diseases in human being. Consequently, opportunistic fungi that were earlier reported from various plants as pathogens are now included under new spectrum of fungal pathogens.

The indiscriminate use of commercial antifungal drugs to treat infectious diseases coupled with resistance of microorganisms against antibiotics has forced the researchers to search for new antimicrobial substances from various sources including medicinal plants ${ }^{[3]}$. Current survey of literature reveals a gradual revival in the use of medicinal and aromatic plants in developed as well as in developing countries. There are 2600 plant species of which more than 700 find use as medicinal herbs $^{[4]}$. Scientific research based on traditional use of medicinal plants indicated that plant-derived essential oils contain active antifungal substances, which could be safe and without side effects for treatment of specific fungal infections ${ }^{[5]}$.

Cocklebur (Xanthium strumarium L.), an annual herb with stout, short and hairy stem, is mainly distributed in China and Europe. In traditional medicine, $X$. strumarium has been used for urticaria, headache, sinusitis, arthritis and emphysema ${ }^{[6-8]}$. All parts of plant possess sedative, diaphoretic and diuretic properties. The plant also shows its efficacy in mitigating long standing cases of malarial fever ${ }^{[9]}$. The genus Xanthium also reported to exhibit antibacterial ${ }^{[10]}$, antiviral ${ }^{[11]}$, antimalarial ${ }^{[12]}$, fungicida ${ }^{[13]}$, insecticida ${ }^{[14]}$ and cytotoxic activities against cancer cell lines ${ }^{[15]}$. Commercially this plant is used in yellow dye manufacturing ${ }^{[16]}$.

The chemical composition of $X$. strumarium has been found to include phenolic compounds as thiazolidinediones, chlorogenic acids, ferulic acids ${ }^{[6]}$, 1,3,5-tri-O-caffeoyl quinic acid, 1,5-di-O-caffeoyl quinic acid, caffeic acid ${ }^{[17]}$, as well as isoprenoids such as strumasterol, $\beta$-sitostero ${ }^{[18]}$, triterpenoid saponins ${ }^{[18]}$, monoterpene, sesquiterpene hydrocarbons ${ }^{[19]}$ and xanthanolide sesquiterpene lactones ${ }^{[20]}$. However, there are few reports documented about the antifungal and fungicidal activity of the oil of $X$. strumarium ${ }^{[13]}$, especially very limited data is available about the locally growing $X$. strumarium Pakistani plant. Therefore, the aim of this work was to analyse chemical composition and to determine antifungal activity of hydrodistilled oil of $X$. strumarium leaves to generate comparable data from Pakistan.
Fresh leaves of $X$. strumarium were collected from the PCSIR Labs Complex, Lahore, Pakistan and authenticated at the Herbarium, Department of Botany, University of Punjab, Lahore, Pakistan. A voucher specimen (code 15081) was also deposited in the herbarium. Anhydrous sodium sulphate, ethanol and methanol used in this study were purchased from Merck (Darmstadt, Germany). Culture media, potato dextrose agar (PDA) and yeast extract peptone dextrose (YPD) broth were purchased from Oxoid Limited, Hampshire, UK.

Air-dried and finely ground plant material was subjected to hydro distillation for $6 \mathrm{~h}$ using Reverse Dean-Stark apparatus ${ }^{[21]}$. Distillate of essential oil was dried over anhydrous sodium sulphate, filtered and stored at $-4^{\circ}$ until analysed. The analysis of the essential oil was carried out using gas chromatography/mass spectrometry (GC/MS) of Agilent Technologies Inc., USA, Model $6890 \mathrm{~N}$, operating in electron ionization mode at $70 \mathrm{eV}$ equipped with a split less injector. Helium is used as a carrier gas at the flow rate of 1 $\mathrm{ml} / \mathrm{min}$ using DB-5 MS $(30 \times 0.25 \mathrm{~mm}$ id, $0.25 \mu$ film thickness) capillary column. The initial temperature was programmed at $50-140^{\circ}$ at the rate of $5^{\circ} / \mathrm{min}$ and then $140-250^{\circ}$ at the rate of $3 \%$ min followed by a constant temperature at $260^{\circ}$ for period of $20 \mathrm{~min}$. Sample $(2 \mu 1)$ was injected to the column programmed at $200^{\circ}$ and resolutions of components were attained. The mass spectrometer is capable of scanning from 35 to 500 atomic mass unit (AMU) every second or less. The data acquisition system continuously acquires and stores all data analyses.

The identification of chemical components was based on the comparison of their mass spectra with those of NIST mass spectral library ${ }^{[22,23]}$ and those described by Adam $^{[24]}$ as well as on comparison of their retention indices (RI) either with those of authentic compounds or with literature values ${ }^{[24]}$.

Six fungal strains with marked Accession No (AN) were purchased from fungal bank, Institute of Agricultural Sciences, University of the Punjab, Lahore, Pakistan to demonstrate antifungal activity of essential oil. All selected fungal strains, Aspergillus niger (AN1109), A. flavus (AN1110), Fusarium oxysporum (AN1175), F. solani (AN1199), Alternaria alternata (AN1200) and Penicillium digitatum (AN1160) were sub-cultured at $25^{\circ}$ for $120 \mathrm{~h}$ on PDA slants to prepare spore suspension before testing antifungal activity.

Antifungal activity of six different concentrations 
of $X$. strumarium essential oil was evaluated by agar well diffusion method on PDA against selected fungal strains ${ }^{[25]}$. Twenty $\mathrm{ml}$ of molten agar medium was inoculated with spore suspension of indicator fungal strain at $10^{6} \mathrm{CFU} / \mathrm{ml}$. The inoculated medium was poured into a petri plate and allowed to solidify. Wells were made on solidified agar and $90 \mu \mathrm{l}$ of the respective concentration of essential oil was added into well to evaluate antifungal and minimum inhibitory concentration (MIC). The plates were incubated at $25^{\circ}$ for $48 \mathrm{~h}$. The diameters of zone of inhibition zones were measured in millimetres and results were recorded in triplicate. MIC was defined as lowest concentration of essential oil to inhibit growth of fungal strains after incubation.

Minimal fungicidal concentration (MFC) was determined by broth dilution method ${ }^{[26]}$. Tubes containing culture broth and oil with concentration of MIC were inoculated with $10^{6} \mathrm{CFU} / \mathrm{ml}$ fungal spores. Tubes with and without respective fungal spore load were used as controls. The tubes were incubated at $25^{\circ}$ for $48 \mathrm{~h}$ to examine any visible turbidity. After incubation, $100 \mu \mathrm{l}$ from tubes showing no visible growth was removed and poured into plates along with agar to calculate total emergent mold counts. The minimum oil concentration that entirely inhibits the fungal growth, killing $99.9 \%$ of the original inoculum after $48 \mathrm{~h}$ of incubation was considered as MFC.

The yield of oil obtained by hydrodistillation was $0.13 \%(\mathrm{v} / \mathrm{w})$, in agreement with Taher et al. ${ }^{[19]}$ who reported a yield of $0.12 \%$. The gas chromatography coupled with mass spectrometry revealed the presence of twenty two compounds. Nine components, $45.20 \%$ of total were identified (Table 1). These components were further classified in two fractions i.e. hydrocarbon fraction and oxygenated fraction. Hydrocarbon fraction constituted $\beta$-caryophyllene, limonene, $\alpha$-muurolene,

TABLE 1: GC/MS ANALYSIS OF ESSENTIAL OIL OF $X$. STRUMARIUM LEAVES

\begin{tabular}{lcc}
\hline Name of components & RI & $\begin{array}{c}\text { Relative \% } \\
\text { In essential } \\
\text { oil }\end{array}$ \\
\hline Limonene & 1032 & 5.66 \\
Copaene & 1377 & 1.47 \\
B-Caryophyllene & 1418 & 17.53 \\
Spathulenol & 1572 & 6.09 \\
a-cadinol & 1652 & 6.66 \\
1,3,5-trimethyl-2[2-nitroallyl]benzene & & 3.29 \\
a-Muurolene & 1499 & 2.08 \\
Phytol & 1821 & 2.42 \\
E,E,Z-1,3,12-nonadecatriene-5,14-diol & & 0.27 \\
\hline
\end{tabular}

copaene and while $\alpha$-cadinol, spathulenol, phytol, 1,3,5-trimethyl-2[2-nitroallyl]benzene and E,E,Z1,3,12-nonadecatriene-5,14-diol comprised the oxygenated fraction of the oil.

In the present study, the major component of the essential oil was found to be $\beta$-caryophyllene $(17.53 \%)$, which did not agree with the previous results in which $\beta$-guaiene ${ }^{[27,28]}$ and limonene ${ }^{[29-31]}$ were reported to be the major components. It is interesting to note that $\beta$-guaiene, which had been reported as major constituent of leaves oil ${ }^{[27,28]}$ was found to be absent in this study. Limonene $(5.66 \%)$ was present in low concentration as compared to previous reports ${ }^{[27-31]}$. Phytol $(2.42 \%)$ concentration was in agreement with an earlier report ${ }^{[28]} \cdot \alpha$-cadinol $(6.66 \%)$, spathulenol $\quad(6.09 \%), 1,3,5$-trimethyl-2[2nitroallyl] benzene $(3.29 \%)$, $\alpha$-muurolene $(2.08 \%)$, copaene $(1.47 \%)$ and E,E,Z-1,3,12-nonadecatriene-5,14diol $(0.27 \%)$, were reported first time from the essential oil of $X$. strumarium.

The antifungal activity of $X$. strumarium essential oil was evaluated by measuring the zone of inhibition against six fungal strains. All assayed concentrations $(8,25,65,100,150$ and $250 \mu \mathrm{g} / \mathrm{ml})$ of oil exhibited remarkable antifungal activity against the tested fungal strains with zones of inhibition ranging from 11.0 to $39.0 \mathrm{~mm}$ (Table 2). However, the degree of inhibition was dependent on the oil concentrations and the fungal strains. Maximum antifungal activity was exhibited against $F$. solani $(16.1-39.0 \mathrm{~mm})$ followed by $P$. digitatum $(11.0-38.1 \mathrm{~mm})$ and $A$. niger (11.2$35.7 \mu \mathrm{mm})$ at $8-250 \mu \mathrm{g} / \mathrm{ml}$ concentrations. The high degree of antifungal activity was further confirmed by MIC and MFC. The observed very low value of MIC as well as MFC i.e. $8 \mu \mathrm{g} / \mathrm{ml}$ revealed that all fungal strains were highly sensitive to $X$. strumarium essential oil (Table 3). According to Duarte et al. ${ }^{[32]}$ proposed plant material classification, based on the MIC results, the oil or plant be regarded as strong inhibitors when MIC is below $0.5 \mathrm{mg} / \mathrm{ml}$, moderate when MIC is in range of $0.6-1.5 \mathrm{mg} / \mathrm{ml}$ and weak when MIC is above $1.6 \mathrm{mg} / \mathrm{ml}$. Considering the plant classification for potential antimicrobial activity reported by Duarte et al. ${ }^{[33]}$, the $X$. strumarium oil with antifungal activity at $8-250 \mu \mathrm{g} / \mathrm{ml}$ concentration against the evaluated fungal strains falls within the group of strong inhibitor plants. These remarkable antifungal and fungicidal results are in agreement with those reported in previous studies $^{[27,33-36]}$, notwithstanding the differences in 

METHOD

\begin{tabular}{lcccccc}
\hline Tested & \multicolumn{5}{c}{ Zone of inhibition $(\mathbf{m m})^{*}$ (fungistatic effect) } \\
\cline { 2 - 7 } fungal strains & $\mathbf{2 5 0} \boldsymbol{\mu g} / \mathrm{ml}$ & $\mathbf{1 5 0} \boldsymbol{\mu g} / \mathrm{ml}$ & $\mathbf{1 0 0} \boldsymbol{\mu g} / \mathrm{ml}$ & $\mathbf{6 5} \boldsymbol{\mu g} / \mathrm{ml}$ & $\mathbf{2 5} \boldsymbol{\mu g} / \mathrm{ml}$ & $\mathbf{8} \boldsymbol{\mu g} / \mathrm{ml}$ \\
\hline A. niger & $35.7 \pm 0.2$ & $25.3 \pm 0.3$ & $20.1 \pm 0.4$ & $14.8 \pm 0.1$ & $12.7 \pm 0.2$ & $11.2 \pm 0.1$ \\
A. flavus & $34.5 \pm 0.3$ & $24.1 \pm 0.3$ & $19.8 \pm 0.7$ & $14.2 \pm 0.1$ & $12.5 \pm 0.3$ & $11.3 \pm 0.1$ \\
F. oxysporum & $31.8 \pm 0.5$ & $23.5 \pm 0.4$ & $18.3 \pm 0.1$ & $15.8 \pm 0.5$ & $12.8 \pm 0.2$ & $11.2 \pm 0.1$ \\
F. solani & $39.0 \pm 0.0$ & $28.5 \pm 0.8$ & $24.8 \pm 0.2$ & $21.5 \pm 0.3$ & $18.8 \pm 0.2$ & $16.1 \pm 0.1$ \\
A. alternata & $30.2 \pm 0.3$ & $26.9 \pm 0.5$ & $22.5 \pm 0.4$ & $19.5 \pm 0.4$ & $16.3 \pm 0.3$ & $15.0 \pm 0.0$ \\
P. digitatum & $38.1 \pm 0.2$ & $27.1 \pm 0.7$ & $18.8 \pm 0.0$ & $14.8 \pm 0.4$ & $12.2 \pm 0.0$ & $11.0 \pm 0.0$ \\
\hline
\end{tabular}

*The diameter of the inhibition zones $(\mathrm{mm})$, including the disc diameter $(6 \mathrm{~mm})$, are given as mean $\pm \mathrm{SD}$ of triplicate experiments

TABLE 3: FUNGICIDAL CONCENTRATION (MFC) OF $X$. STRUMARIUM ESSENTIAL OIL

\begin{tabular}{lcc}
\hline Tested fungal strains & MIC $(\mu \mathrm{g} / \mathrm{ml})$ & MFC $(\mu \mathrm{g} / \mathrm{ml})$ \\
\hline A. niger & 8 & 8 \\
A. flavus & 8 & 8 \\
F. oxysporum & 8 & 8 \\
F. solani & 8 & 8 \\
A. alternate & 8 & 8 \\
P. digitatum & 8 & 8 \\
\hline
\end{tabular}

selected fungal strains and the method used to evaluate antifungal activity.

Phytopharmacological research approach on the biological activity possessed by the essential oil has disclosed that chemical composition of the essential oil could be linked with the antimicrobial activity and the reported therapeutic effects. The sesquiterpene $\beta$-caryophyllene, the most abundant constituents found in our essential oil was extensively investigated because of its several biological activities, including antimicrobial ${ }^{[37,38]}$, insecticidal ${ }^{[39,40]}$, antiinflammatory ${ }^{[41,42]}$, anticarcinogenic ${ }^{[43-47]}$ and local anesthetic ${ }^{[48]}$ activities. Limonene present in appreciable amounts $(5.66 \%)$ in our oil efficient in inhibiting the proliferation of a variety of microorganisms that cause food spoilage ${ }^{[49]}$. The antimicrobial activity of phytol against eight bacterial and eight fungal strains was investigated by Pejin et al. ${ }^{[50]}$. It was proven that phytol to be active against all tested bacteria and fungi. According to Nada et al. ${ }^{[51]}$ and Tabanca et al. ${ }^{[52]}$ spathulenol, demonstrated significant antimicrobial activity. Ho et al. ${ }^{[33]}$ demonstrated that $\alpha$-cadinol has antifungal activity. 1,3,5-trimethyl-2[2nitroallyl] benzene, $\alpha$ - muurolene, copaene and E,E,Z-1,3,12nonadecatriene-5,14-diol present in our essential oil but there is no data available on their antimicrobial activity. From the results obtained in this investigation, it can be concluded that antifungal activity of the essential oil of $X$. strumarium leaves could be attributed to the presence of sesquiterpenes and oxygenated terpenes. The strong antifungal activity might be due to a possible synergetic effect of compounds, which were identified for the first time in this essential oil.

Reported results of this study revealed that the essential oil of $X$. strumarium possessed antifungal activity against a wide spectrum of fungal strains. Remarkable growth inhibition of tested fungal strains suggested that $X$. strumarium could serve as a starting point for finding selective antifungal agents, which could have potential clinical applications in the treatment of fungal infectious diseases.

\section{Conflict of interests:}

Authors report no conflict of interests.

\section{Financial support and sponsorship:}

Nil.

\section{REFERENCES}

1. Davies J. Inactivation of antibiotic and the dissemination of resistance genes. Science 1994;264:375-82.

2. Singh N. Trends in the epidemiology of opportunistic fungal infections: predisposing factors and the impact of antimicrobial use practices. Clin Infect Diseases 2001;33:1692-6.

3. Bauer AW, Kirby WM, Sherris JC, Turck M. Antibiotic susceptibility testing by standardized single disc method. Am J Clin Pathol 1996;44:493-6.

4. Ali-Shtayeh MS, Abu Ghdeib SI. Antimycotic activity of twenty-two plants used in folkloric medicine in the Palestinian area for the treatment of skin diseases suggestive of dermatophyte infection. Mycoses 1999;42:665-72.

5. Sunita B, Mahendra R. Antifungal activity of essential oils from Indian medicinal plants against human pathogenic Aspergillus fumigatus and A. niger. World J Med Sci 2008;3:81-88.

6. Qin L, Han T, Li H, Zhang Q, Zheng H. A new thiazinedione from Xanthium strumarium. Fitoterapia 2006;77:245-6.

7. Han T, Li HL, Zhang QY, Haa P, Zheng HC, Rahman K, et al. Bioactivity guided fractionation for antiinflammatory and analgesic properties and constituents of Xanthium strumarium L. Phytomedicine 2007;14:825-9.

8. Yoon JH, Lim HJ, Lee HJ, Kim HD, Jeon R, Ryu JH. Inhibition of lipopolysaccharide-induced inducible nitric oxide 
synthase and cyclooxygenase-2 expression by xanthanolides isolated from Xanthium strumarium. Bioorg Med Chem Lett 2003;18:2179-82.

9. Sharma R. Medicinal Plants of India. India: Daya Publishing House; 2003. p. 5.

10. Talakal TS, Dwivedi SK, Sharma SR. In vitro and in vivo antitrypanosomal activity of Xanthium strumarium leaves. Ethnopharmacol 1995;49:141-5.

11. Tsankova ET, Trendafilova AB, Kujumgiev AI, Galabov AS, Robeva PR. Xanthanolides of Xanthium italicum Moretti and their biological activity. Z Naturforsch C 1994;49:154-5.

12. Joshi SP, Rojatkar SR, Nagasampagi BA. Antimalarial activity of Xanthium strumarium. J Med Aromatic Plant Sci 1997;19:366-68.

13. Ginesta-Peris E, Garcia-Breijo FJ, Primo-Yufera E. Antimicrobial activity of xanthatin from Xanthium spinosum L. Lett Appl Microbial 1994;18:206-8.

14. Kamboj A, Saluja AK. Phytopharmacological review of Xanthium strumarium L. (Cocklebur). Inter J Green Pharma 2010;4:129-39.

15. Kinghorn AD, Farnsworth NR, Soejarto DD, Cordell GA, Pezzuto JM, Udeani GO, et al. Novel strategies for the discovery of plant derived anticancer agents. Pure Appl Chem 1999;71:1611-18.

16. Shah FR, Ahmad N, Zahid DM, Masood KR, Ahmad SS. The hudiara drain waste water effect on the distribution of surrounding herbaceous vegetation. Pak J Bot 2010;42:1745-54.

17. Bisht NPS, Singh R. Chemical investigation of the leaves of Xanthium strumarium L. J Indian Chem Soc 1977;54:797-8.

18. Yadava RN, Jharbade J. Novel biologically active triterpenoid saponin from the leaves of Xanthium strumarium Linn. Asian J Chem 2007;19:1224-30.

19. Taher HA, Ubiergo GO, Talenti ECJ. Constituents of the essential oil of Xanthium strumarium. J Nat Prod 1985;48:857-67.

20. Sheu S, Hsu F, Tai H, Sheu M, Huang M. Determination of xanthii constituents by high performance liquid chromatography and capillary electrophoresis. J Food Drug Anal 2003;11:67-71.

21. Sattar A. Extraction and processing technology of essential oils. Proceedings: $1^{\text {st }}$ national symposium of essential oils perfumes and flavours; 1989, p. 7-10.

22. http://www.nist.gov/srd/nlstla.htm.

23. Massada Y. Analysis of Essential Oils by Gas Chromatography and Mass Spectrometry. New York: Wiley; 1976.

24. Adam RP. Identification of essential oils components by gas chromatography/quadrupole mass spectroscopy. Carol Stream (IL): Allured Publishing Corp; 2001.

25. Zakia L. Spices and herbs: Their antimicrobial activity and its determination. J Food Saf 1988;9:97.

26. Rabe T, Mullholland D, Van SJ. Isolation and identification of antibacterial compounds from Vernonia colorata leaves. J Ethnopharmacol 2002;80:91.

27. Sharifi-Rad J, Hoseini-Alfatemi SM, Sharifi-Rad M, SharifiRad M, Marcello I, Sharifi-Rad M, et al. Phytochemical compositions and biological activities of essential oil from Xanthium strumarium L. Molecules 2015;20:7034-47.

28. Scherer R, Wagner R, Meireles MAA, Godoy HT, Duarte MCT, Filho JT. Biological activity and chemical composition of hydrodistilled and supercritical extracts of Xanthium strumarium L. leaves. J Essent Oil Res 2010;22:424-9.

29. Esmaeili A, Rustaiyan A, Akbari MT, Moazami N, Masoudi $\mathrm{S}$, Amiri H. Composition of the essential oils of Xanthium strumarium L. and Cetaurea solstitialis L. from Iran. J Essent Oil Res 2006;18:427-9.

30. Habibi Z, Laleh A, Masoudi S, Rustaiyan A. Composition of essential oil of Xanthium, Brasilium vellozo from Iran. J Essential Oil Res 2004;16:31-2.

31. Cole RJ, Stuart BP, Lansden JA, Cox RH. Isolation and redefinition of the toxic agent from cocklebur Xanthium strumarium. J Agric Food Chem 1980;28:1330-2.

32. Duarte MCT, Figueira GM, Sartoratto A, Rehder VLC, Delarmelina C. Anticandida activity of Brazilian medicinal plants. J Ethnopharmacol 2005;97:305-31.

33. Amerjothy S, Ezhilarasi R, Shanmugakumar SD. Antimicrobial assay of the leaf extracts of Xanthium indicum Koen. Pharmacogn Mag 2007;11:197.

34. Fazli K, Zafar I, Ayub K, Zakiullah, Fazli N, Shafiq MK. Validation of some of the ethnopharmacological uses of Xanthium strumarium and Duchesnea indica. Pak J Bot 2012;44:1199-201.

35. Kishore N, Dubey NK, Tripathi RD, Singh SK. Fungitoxicity of the leaf extracts of some higher plants against Fusarium moniliforme. Natl Acad Sci Lett 1982;5:9-10.

36. Sayema K. Antimicrobial and antioxidant effects of the chloroform extracts of Xanthium strumarium (L.) Int $\mathrm{J}$ of Pharmcol Res 2014;4:83-7.

37. Goren AC, Piozzi F, Akcicek E, Kılıç T, ÇarıkçI S, Mozioglu E, et al. Essential oil composition of twenty-two Stachys species (mountain tea) and their biological activities. Phytochem Lett 2011;4:448-53.

38. Cheng SS, Wu CL, Chang HT, Kao YT, Chang ST. Antitermitic and antifungal activities of essential oil of Calocedrus formosana leaf and its composition. J Chem Ecol 2004;30:1957-67.

39. Rodilla JM, Tinoco MT, Morais JC, Gimenez C, Cabrera R, Martín-Benito D, et al. Laurus novocanariensis essential oil: Seasonal variation and valorization. Biochem Syst Eco 2008;36:167-76.

40. Omolo MO, Okinyo D, Ndiege IO, Lwande WL, Hassanali A. Repellency of essential oils of some Kenyan plants against Anopheles gambiae. Phytochem 2004;65:2797-802.

41. Tung YT, Chua MT, Wang SY, Chang ST. Antiinflammation activities of essential oil and its constituents from indigenous Cinnamon (Cinnamomun osmophloeum) twigs. Bioresour Technol 2008;99:3908-13.

42. Chavan MJ, Wakte PS, Shinde DB. Analgesic and antiinflammatory activity of caryophylleneoxide from Annona squamosa L. bark. Phytomedicine 2010;17:149-51.

43. Silva SL, Figueiredo PMS, Yano T. Chemotherapeutic potential of the volatile oils from Zanthoxylum rhoifolium Lam leaves. Eur J Pharmacol 2007;576:180-8.

44. Kubo I, Chaudhuri SK, Kubo Y, Sanchez Y, Ogura T, Saito $\mathrm{T}$, et al. Cytotoxic and antioxidative sesquiterpenoids from Heterotheca inuloides. Planta Med 1996;62:427-30.

45. Zheng GQ, Kenney PM, Lam LKT. Sesquiterpenes from clove (Eugenia caryophyllata) as potential anticarcinogenic agents. J Nat Prod 1992;55:999-1003. 
46. Di Sotto A, Mazzanti G, Carbone F, Hrelia P, Maffei F. Inhibition by $\beta$-caryophyllene of ethyl methane sulfonateinduced clastogenicity in cultured human lymphocytes. Mutat Res 2010;699:23-8.

47. Legault J, Pichette A. Potentiating effect of $\beta$-caryophyllene on anticancer activity of $\alpha$-humulene, isocaryophyllene and paclitaxel. J Pharm Pharmacol 2007;59:1643-7.

48. Ghelardini C, Galeotti N, Mannelli LDC, Mazzanti G, Bartolini A. Local anaesthetic activity of $\beta$-caryophyllene. Farmaco 2001;56:387-89.

49. Aggarwal KK, Khanuja SPS, Ahmad A, Kumar TRS, Gupta VK, Kumar S. Antimicrobial activity profiles of the two enantiomers of limonene and carvone isolated from theoils of Mentha spicita and Anethum sowa. Flavour Frag J 2002;17:59-63.
50. Pejina B, Savica A, Sokovicb M, Glamoclijab J, Ciricb A, Nikolicb $\mathrm{M}$, et al. Further in vitro evaluation of antiradical and antimicrobial activities of phytol. Nat Prod Res 2014;28:372-6.

51. Nada B, Mirjana S, Valerija D. Phytochemical composition and antimicrobial activity of Satureja montana L. and Satureja cuneifolia ten essential oils. Acta Bot Croat 2005;64:313-22.

52. Tabanca N, Demirci F, Demirci B, Wedge DE, Can Baser KH. Composition, enantiomeric distribution and antimicrobial activity of Tanacetum argenteum subsp. flabellifolium essential oil. J Pharm Biomed Anal 2007;45:714-19.

53. Ho CL, Liao PC, Wang EI, Su YC. Composition and antifungal activities of the leaf essential oil of Neolitsea parvigemma from Taiwan. Nat Prod Commun 2011;6:1357-60. 